they are bounded by no membranous wall; and, when one of the threads comes in contact with an organic particle in the water, the particle sinks into it, and then the thread begins to flow back again into the body of the animal bearing the particle with it, as a stream of treacle might entangle, and carry along a crumb of bread.

The organic particles are introduced into the body, into any part of it, and there they are dissolved and assimilated. I believe that the granules observed in the gelatinous substance are particles of the various products of this assimilation, and that the living matter is perfectly homogeneous and transparent. If the creatures be kept for a few days in water nearly pure, they become less and less granular.

If the thread-like pseudo-podia, as they are called, be rudely touched, they at once contract, and flow rapidly back into their test. The membranous test cannot be truly regarded as a part of the animal, it is a mere excreted defensive covering incapable of any further change, or of manifesting any of the phenomena of life. The body of the animal can be easily squeezed out of it entire, and in that case it shortly begins the excretion of a new shield.

Here, then, we have a homogeneous substance which has the power of inducing and controlling chemical and physical forces, and of moulding into indefinite form the products of the regilated changes taking place within it, which therefore possesses life. The gelatinous matter which in this animal and in the whole sub-kingdom to which it belongs can thus feed and digest without a mouth or stomach, contract without muscles, display irritability without a nervous system-in fact, exhibit all the essential phenomena of living beings without a trace of organisation, is Protoplasm.

If now, laying aside the Gromia, we examine with the micro. scope the water-plant on which we found it, we find that the whole plant from end to end and in all its parts is honeycombed, that is to say, composed of a congeries of minute chambers separated from one another by well-clefined walls, the walls giving the plant its support and consistency.

We place in the field of the microscope a small portion of the rrowing point of a leaf or stem, and we easily make out that the chambers are minute vesicles each complete in itself, adhering according to a definite arrangement to one another. As these cells have occupied a very prominent position in modern histological and physiological speculation, having been re: garded, and being still regarded by many as the units of organisation, the centres and sources of all vital activity, I should wish to sketch distinctly their structure and properties. It is of no consequence whence the cell is selected. All vegetable cells appear to have the same structure at first, during their growth and while their vitality lasts ; subsequently most of them undergo great changes, their walls being thicker and their cavities clogged with various secretions. There are some beautiful transparent-beaded hairs at the bottom of the flower cup of the white variety of the Virginian spider-wort. If we place one of these hairs in a drop of water in the field of the microscope, we find that it is simply composed of a row of oval cells attached end to end. The cell is in this case a minute vesicle with an extremely thin transparent wall. This wall consists of cellulose, a substance composed of thirty-six parts of carbon and thirty parts of water. The membrane is perfectly structureless under the highest powers of the microscope, and apparently continuous. It must, however, be minutely perforated, for water and various secretions and excretions pass through it freely. From its composition and structure it is impossible to imagine that vital force should reside in the vegetable cell-wall. We must regard it as an excretion of dead matter moulded as a boundary wall to the cell cavity by some external agent, but incapable of originating any vital action. The cell is full of water or mucous solution, and watching carefully with a proper arrangement of the light, and a moderately high power, we can distinctly trace threads of dense gelatinous matter moving slowly into the inner surface of the cell-wall. These streams commence wider in the region of a. nucleus, which was at one time regarded as the heart of the cell, as it were, the centre of its vital activity, and gradually branch and diminish at a distance from it. Under the microscope granules appear in these streams, and with these granules em. bedded in them, as crumbs are embedded in a stream of treacle, the currents flow round and round the cell, the granules gradually disappearing and being absorbed. The observations of Prof. Max Schultze and of others have, I think, placed it beyond a doubt that this gelatinous substance occurring within the living cell, and forming, at all events, a large proportion of the cell-contents, is identical with the protoplasm which forms the entire substance of such an animal form as Gromia.

The necklace-like hair of the spider-wort is, in fact, a chain of cells with dead cellulose walls, and each with a living Gromia body imprisoned within it.

Now, although the power which plants possess of fixing carbon and combining it witl 2 the elements of water, is the character which practically distinguishes the Vegetable from the Animal kingdom, I have already shown that we cannot regard this as by any means a universal test. In this respect broomrapes and dodders are animals.

When we pass down by any path we choose, either through animals or plants, we come equally to a great series of very simple forms-mere little masses of protoplasm with a nucleus. Some of these contain peculiarly formed masses of bright colouring matter, green, scarlet, or yellow, and with the possession of such pigment we usually associate the power of decomposing carbonic acid. Many of these bodies have, however, no colouring matter at all, except what is derived from their food. A large number of these simple forms are enclosed in a wall of cellulose, but very many of them are naked or merely covered with a pellicle of fimer protoplasm ; while some, such as the plasmodia of the myxogastric fungi are, for some part of their lives, enclosed in a cellulose wall, and for another part, naked. Going still lower, we have Haeckel's Monera, differing from the others merely in the absence of a nucleus and the total wrant of differentiation of any part. Even these last are sometimes coloured, and from their chemical reactions it seems very likely that they possess some low form of the peculiar vegetable power. Now, the question is, whether all these considerations lead in any way in the direction of establishing a separate kingdom for these simple beings. I think decidedly not, but it seems to me that they prove almost to demonstration that organic nature must be taken as one whole, that the Animal and Vegetable kingdoms are absolutely continuous, and that a tree flinging its green flags into the sunshine and feeding on the winds of heaven, is essen. tially nothing more than a vast colony of a protozoon, com. parable to a gigantic nummulite, only building a cellulose instead of a calcareous shell, and developing a special secretion in special -organs for the purpose of enabling it to do.so.

\section{MR. BENTHAM'S ANNIVERSARY ADDRESS TO THE LINNEAN SOCIETY}

IAVING now for the tenth time the honour of addressing you from this chair on the occasion of your annual gathering, it has been my wish to lay before you a general sketch of the progress making in systematic Biology, the foundation upon which must rest the theoretical and speculative, as well as the practical, branches of the science, to report upon the efforts made further to investigate, establish, and extend that foundation, and to convert the numerous quicksands with which it is beset into solid rock. This subject formed the chief portion of my address of 1862 , and again of those of 1866 and 1868 ; but on the present occasion I have had some difficulties to contend with. Mr. Dallas, to whose kindness I owed the zuological notes I required, has now duties which fully absorb his time, and I have been obliged to apply to foreign correspondents, as well as to my zoological friends at home, for the necessary information. They have one and all responded to my call with a readiness for which I cannot too heartily express my thanks; and if there is some diversity in the extent and nature of the information $I$ have received from different countries, which may prevent any very correct estimate of the comparative progress made in them, it is owing to the questions which I put having been stated too generally, and, though sent in the same words to my different correspondents, they have been differently understood by them. In such a review, however, as I am able to prepare, I propose chiefly to consider the relative progress made by zoologists and botanists in the methods pursued and the results obtained, in the first place as to general works common to all countries, and secondly as to those which are more particularly worked out in or more specially relate to each of the principal states or nations where biological science is pursued, prefacing this review by a few general remarks supplementary to those I laid before you in my first address in 1862 .

Since that time systematic biology has to a certain degree been cast into the background by the great impulse given to the more speculative branches of the science by the promulgation of the 
Darwinian theories. The great thunclerbolt had indeed been launched, but had not yet produced its full effect. We systematists, bred up in the doctrine of the fixed immutability of species within positive limits, who had always thought it one great object to ascertain what those limits were, and by what means species, in their never-ending variations and constant attempts to overstep those limits, were invariably checked and thrown back within their own domain, might at first have been disposed to resist the revolutionary tendency of the new doctrine; but we felt shaken and puzzled. The wide field opened for the exercise of speculative tendencies was soon overrun by numerous aspirants, a cry of contempt was raised against museum zoologists and herbarium botanists, and nothing was allowed to be scientific which was not theoretical or microscopical. But this has been carried, in some instances, too far. If facts without deductions are of little avail, assumptions without facts are worse than useless. Theorists in their disputes must bring forth the evidences they rely upon, and these evidences can only be derived from and tested by sound systematic biology, which must resume and is resuming its proper position in the ranks of science, controlled and guided in its course by the results of those theories, for which it has supplied the basis. * If the absolute immutability of races is no longer to be relied upon, the greater number of them (whether genera, species, or varieties) are at the present or any other geological period, practically circumscribed within more or less definite limits. The ascertaining those limits in every detail of form, structure, habit, and constitution, and the judicious appreciation of the very complicated relations born to each other by the different races so limited, is as necessary as the supplementing the scantiness of data from the depths of Teutonic consciousness by the vivid flashes of Italian imagination, or as the magr. nifying minute as yet undeveloped organisms, with a precision beyond what is fully justified by our best instruments.

I am, however, far from denying on the one hand how much biological science has of late been raised, since it has been brunght to bear through well-developed theories and hypotheses upon the history of our globe, and of the races it has borne; and on the other, how very much the basis upon which it rests has been improved and consolidated by the assiduous use of the microscope and the dissecting knife; but I would insist upon the necessity of equal ability being applied to the intermediate process of method or nomenclature and classification, which forms the connecting link between the labours of the anatomist and the theorist, reducing the observations of the one to forms available for the arguments of the other. All three, the minute observer, the systematist, and the theorist, thus assisting each other, equally contribute to the general advancement of science, and for all practical application, the systematist's share of duty is certainly the most important.

The quicksands to which I have alluded to as besetting thus the foundlation of biological science, may be classed as imperfect data and false data, imperfect method and false method. To show what progress is making in removing or consolidating them, it may be useful to consider what these data are, and what are our means of fixing them so as to be readily available for use.

It must, in the first place, be remembered that the races whose relations to each other we study, can only be present to our minds in an abstract form. In treating of a genus, a species, or a variety, it is not enough to have one individual before our eyes, we must combine the properties belonging to the whole race we are considering, abstracted from those peculiar to subordinate races or individuals. We cannot form a correct idea of a species from a single individual, nor of a genus from a single one of its species. We can no more set up a typical species than a typical individual. If we had before us an exact individual representative of the common parent from which all the individuals of a species or all the species of a genus have descended-or if you prefer it an exact copy of the model or type after which the whole species or genus had been created, we should have no possible means of recognising it. I once heard a lecture of a German philosophical naturalist of considerable reputation in his day, in which he thought he proved that the common Clover was the type of Papilionaceæ. His facts were correct enough, but his arguments might have been turned in favour of any other individual species that might have been selected. Suppose two individuals of a species, two species of a

* The great importance of morphology and classification, the elements of systematic biology, has been forcibly illustrated by Prof. Flower in his last year's introductory lecture at the Royal College of Surgeons. genus, two genera of a family, in one of which certain organs are more developed, more differentiated, or more consolidated than in the other, if we agree upon the first question of which is the most perfect, a point upon which naturalists seldom do agree, how are we to determine which represents the common parent or model? whether the perfect one is an improvement upon, or an improved copy, or the imperfect one a degeneracy from or a bad imitation of the other? No direct evidence goes beyond a very few generations, reasoning from analogy is impossible without direct evidence to start from, and the imagining a type without either is the business of the poet, not of the naturalist.

It follows that every such abstract idea of a race must be derived from the observation, by ourselves or by others, of as large a number of the constituent individuals as possible. However fixed a race may be, if fixed at all in Nature, that is not the case with our abstract idea of it, no species or genus we establish can be considered as absolutely fixed, it will ever have to be com- $^{-}$ pleted, corrected, or modified, as more and more indiv duals come to be correctly observed. Ifence it is, that a species described from a single specimen, and even a genus established on a single species, always excites more or less of suspicion unless supported by strong reasoning from analogy or confirmed by repeated observation.

Our means of observing and methodising biological facts, of establishing and classifying those abstract icleas we call varieties, species, genera, families \&c., consist in the study (I) of living individual organisms; (2) of preserved specimens; (3) of pictorial delineations; and (4) of written descriptions. Each of these sources of information has its special advantages, but each is attended by some special deficiencies to be supplied by one or more of the others:

I. The study of living individuals in their natural state is with. out doubt the most satisfactory, but very few such individuals can be simultaneously observed for the purpose of comparison, and no one individual, at any one moment, can supply the whole of the data required relating even to that individual. Some additional facilities in these respects are given by the maintenance of collections of living animals and plants, particularly useful in affording the means of continuous observation during the various phases of the life of one and the same individual, and sometimes through successive generations, or ir facilitating the internal examination of organisms immediately after death, when the great physiological changes consequent upon death have only commenced. But there are drawbacks and difficulties to be overcome, as well as a few special sources of error to be guarded against, and in this respect, as well as in the progress recently made in their application to science, there is a marked difference between zoological and botanical living collections, or so-called gardens.

The great drawback to living collections, especially zoological, is their necessary incompleteness. At the best it is individuals only, not species, and in a few cases genera that are exposed to observation; genera, indeed, can always be better represented than species, for a few species bear a much larger proportion to the total number contained in a genus, than a few individuals to the total number which a species contains. Whole classes are entirely wanting in zoological gardens, which are usually limited to vertebrata. Of late years means have been found to include a few aquatic animals of the lower orders, but insects, for instance, those animals which exercise the greatest infuence on the general economy of nature, the observation of whose life and transformations is every day acquiring greater importance, are wholly unrepresented in zoological gardens. The shortness of duration of their individual lives, their enor. mous power of propagation, the different mediums in which they pass the different stages of their existence, will long be obstacles to the formation of living entomological collections on anythin like a satisfactory scale. The cost also of the formation and maintenance of living collections is very much greater in the case of animals than of plants; but on the other hand zoologists have the advantage of the attractiveness of their menageries to the general unscientific but paying public, and, under judicious management, some sacrifices to popular tastes are far outweighed by the additional funds obtained towards rendering their collec tions useful to science.

The false data or errors to be guarded against in the observation of living zoological collections are chiefly owing to the unnatural conditions in which the animals are placed. Ungenial climate, unaccustomed food, want of exercise, \&c., act upon their temper, habits, and constitution, and confinement materially 
modifies circumstances connected with their propagation. Such errors or false data are, no doubt, as yet very few and unimportant compared to those which have arisen from the reliance on garden plants for botanical observations, but, as zoological gardens multiply and extend, they will have to be more and more kept in view.

In my younger days there were already a number of small collections of living animals, but almost all either travelling or local menageries exhibited for money by private individuals, or small collections kept up as a matter of curiosity for the benefit of the public, such as those of the Pfanen-Insel at Potsdam, the park at Portici, or our own Tower menagerie. At Paris alone, at the Jardin des Plantes, in the flourishing days of the Jussieus and Cuviers, was the living zoological collection rendered essentially subservient to the purposes of science. Since then, howeven, matters have much changed : the Jardin des Plantes, which so long reigned stipreme, has, by remaining stationary, sunk into a second rank. She may indeed be as justly as ever prond of her Milne-Edwards, her Brongniart, her Decaisne, and many others, but long out of favour with the Government and the paying public, who transferred their patronage to the high-sounding Jardin d'Acclimatation, now no more, she has been almost abandoned to the resources of pure science, always of the most restricted in a pecuniary point of view. We in the mean time, and after our example several continental states or cities, have made great advances. The formation of our Zoological Society and Gardens opened a new era in the cultivation of the science. After various vicissitudes, the Society had the good fortune to secure the services of one who combined in the highest degree zoological eminence with administrative ability, and thus our great living zoological collection is now raised to the proud relative position which the Jardin des Plantes once held, and which there seems every reason to hope it will long maintain. With an annual income of about $23,000 l$. the Zoological Society is enabled to maintain a living collection of about a thousand species of Vertebrata, and although some portion of the surplus funds is necessarily applied for the sole gratification of the paying public, yet a fair share is devoted to the real promotion of that science for which all the fellows are supposed to subscribe, the accurate ob. servation of the animals maintained, the dissection of those that die, and the publication of the results. Physiological experiments are either actually made in the garden, or promoted and liberally assisted, such, for instance, as those on the transfusion of blood, the effects or non-effects of which were recently laid before the Royal Society by Mr. F. Galton. A very rich zoological library has been formed, and last year's accounts show a sum of about $x, 800 \%$. expended in the Society's scientific publications.

Zoological gardens, after the example of the London one, have been established not only in several of our provincial towns, but in various continental cities, amongst which the more important ones, as I am informed, are those of Amsterdam, Antwerp, Hamburgh, Cologne, Frankfort, Berlin, Rotterdam, and Dresden; the receipts of the one at Hamburgh, for instance, amounting annually, according to the published reports, to between $8,000 l$. and $9,000 l$. There are also so-called gardens of acclimathe have not much of a scientific character; their professed object indeed is not so much the observation of the physiology and constitution of animals as their modification for practical purposes, and practically they are cbiefly known as places of recreation, and are not always very successful. The great one in the Boir de Boulogne, now destroyed, out of an expenditure in I 868 of about $7,200 l$. showed a deficit of about I $600 \%$; a smaller one at the Hague is enabled to pay an annual dividend to its shareholders.

Living collections of plants have great advantages over those of animals, they can be so much more extensively maintained at a comparatively small cost. In several botanical gardens several thousand species have been readily cultivated at a comparatively small cost, and species can be represented by a considerable number of individuals, a great gain especially where instruction is the immediate object, the lives of many can be watched horougli several successive generations, and great facilities are afforded for physiological experiments and nicroscopical observations on plants and their organs whilst still retaining more or less of life. On the other hand the false data recorded from observations made in botanical gardens have been ]amentably numerous and important. A plant in the course of its life soalters its outer aspect that each one cannot be individtialised by the keeper of a large collection, and at one period, that of the seed in the ground, it is wholly withdrawn from his observation. $\mathrm{He}$ is therefore obliged to trust to labels, these are often mismatched by accident or by the carelessness of the workmen employed, or again, one seed has been sown and another has come up in its place, or a perennial has perished and made room for a sucker or seedling from an adjoining species. The misnomers arising from these and other causes have become perpetuated and sanctioned by directors who, for want of adequate libraries or herbaria, or sometimes for want of experience or ability, have been unable to detect them. Plants have also been so disguised or essentially altered by cultivation that it has become difficult to recognise their identity, and new varieties or bybrids, which, if left to themselves, would have succumbed to some of the innumerable causes of destruction they are constantly exposed to in a wild state, have been preserved and propagated through the protective care of the culcivator, and pronounced at once to be new species. If, more. over, a misplaced label indicates that the seed has been received from a country where no plants of a similar type are known to grow, the director readily notes it as a new genus, and, prond of the discovery, gives it a name and appends a so-called diagnosis to his next seed-catalogue, adding one more to the numerous puzzles with which the science is encumbered. So far, indeed, had this nuisance been camied in several Continental gardens in the earlier portion of the present century, that, excepting perhaps Fischer and Meyer's and a few other first-rate indexes, the great majority, perhaps nine-tenths, of the new species published in these catalogues have proved untenable, and, from my own experience, I am now obliged, a priori, to set down as doubtful every species established on a garden plant without confirmation from wild specimens. Fortunately the custom is now abating, and directors of botanic gardens are beginning to perceive that they do not add to their reputation by having their names appended to those of bad species.

Living collections of plants, or botanical gardens, are of much older date than zoological ones, and since the sixteenth century have been attached to the principal universities which have medical schools, that of Padua, dating from 1525 , that of Pisa, from I544, and of Montpellier, from 1597. The Jardin des Plantes of Paris, which in botany, even more than in zoology, so long reigned supreme, was established in 1610 , our own first one at Oxford in 1632 . These university gardens having been generally more or less under the control of eminent resident botanists, have contributed very largely to the means of studying the structure and affinities of plants, especially in those Continental cities where a milder or more steady climate has facilitated the maintenance of large collections in the open air or with little protection. Continental gardens have also been long and are still made largely available for the purpose of instruction as well as of scientific experiments, of which the recent labours of Naudin and Decaisne are an excellent illustration. For these scientific purposes the arrangement in large and small square compartments is peculiarly suitable, and $I$ confess that I have frequently bad greater pleasure in witnessing the facilities afforded to zealous students in following up, book in hand, the straight rows of scientifically-arranged plants in these formal university gardens, than in watching the gay crowds that flock to the more ornamentally laid out public botanic gardens.

I do not think that generally much advance has been made of late years in Continental botanical gardens. Those that I first visited in 1830 appeared to me to be but little improved when I again went over them in 1869 . Some have acquired additional space, others have paid more attention to ornament, but most have remained nearly stationary, and a few have even fallen back. In our own country we have minde great progress. Kew Gardens had indeed, in former days, rendered assistance to the investigations of Robert Brown and a few other favoured individuals, but they were the Sovereign's private property, and were kept very close, with little encouragement to science at large. But thirty years' unceasing exertions on the part of its distinguished. directors, the two Hookers, father and son, have raised them to a point of scientific usefulness far beyond any other establishment of the kind at home or abroad. Of the large sums annually voted for it by Parliament, a portion has indeed to be applied to mere ornament and to the gratification of visitors, but yet, with all the drawbacks of our climate and consequent expenditure in honses, the largest named collection of species ever brought together in one spot, representatives of all parts of the globe, are there maintained, freely exhibited to the public, and submitted to the examination of scientific botanists.

(To be continuest) 